\title{
Analysis of selected problems of biomass combustion process in batch boilers - experimental and numerical approach
}

\author{
Mateusz Szubel ${ }^{1, a}$ \\ ${ }^{1}$ AGH University of Science and Technology, Faculty of Energy and Fuels, al. Mickiewicza 30, 30-059 Krakow, Poland
}

\begin{abstract}
It is possible to list numerous groups of heating units that are used in households, such as boilers, stoves and units used as supporting heat sources, namely fireplaces. In each case, however, the same operational problems may be evoked [1]. To understand the causes of energy losses in a boiler system, a proper definition of significant elements of the unit's heat balance is necessary. In the group of energy losses, the flue gas loss and the incomplete combustion loss are the most significant factors. The problem with the loss resulting from incomplete combustion, which is related to the presence of combustible substances in the exhaust, is especially significant in case of biomass boilers [2,3]. The paper presents results of the research and the optimisation of the biomass combustion process in the $180 \mathrm{~kW}$ batch boiler. The studies described have been focused on the reduction of the pollutants emission, which was primarily realised by the modifications of the air feeding system. Results of the experiments and the CFD simulations have been compared and discussed. Both in case of the model as well as the experiment, positive influence of the modifications on the emission have been observed.
\end{abstract}

\section{Introduction}

From the physicochemical point of view, the biomass combustion process can be divided into four stages: heating and drying of the fuel, its thermal decomposition, combustion of released volatiles and combustion of solid residues [4].

Fuel heating proceeds as a result of the radiation of the flame and the walls of the combustion chamber. Then, the fuel is dried in the temperature of $100{ }^{\circ} \mathrm{C}$ (evaporated water is carried away with the exhaust gas to the chimney).

The process of thermal decomposition depends on the composition of the compounds, such as hemicellulose, cellulose and lignin. Decomposition of hemicellulose occurs in temperatures $150-260{ }^{\circ} \mathrm{C}$. Because cellulose and lignin are more stable, thermal decomposition of these compounds occurs in higher temperatures (240-350 ${ }^{\circ} \mathrm{C}$ and $280-500{ }^{\circ} \mathrm{C}$, respectively) [4].

The composition of the gaseous substance released from the biomass fuel depends on the ratio of oxygen available and the amount of oxygen that would allow to complete the burning process, which is called "the equivalence ratio". For equivalence ratios below 0.1 , pyrolysis occurs. In such a way, a significant fraction of the biomass energy is found in the char and oily residues. In case of the equivalence ratios between 0.2 and 0.4 , the process is called the proper gasification (maximum energy is transferred to the gas) [5].
Carbon monoxide constitutes a major component of the biomass gasification products. It is oxidized to carbon dioxide $\left(\mathrm{CO}_{2}\right)$ in the secondary combustion region. It should be noted, that combustion of high purity carbon monoxide $(\mathrm{CO})$, without moisture, hydrogen and hydrocarbons occurs in a slow manner - the oxidation of $\mathrm{CO}$ is catalysed even by trace amounts of hydrogen and its compounds [6].

Currently, attention of the producers of biomass batch boilers is mostly focused on the problem of $\mathrm{CO}$ emissions as well as particle matters emissions. Due to the European Union regulations, the emissions referred to above have to be kept at certain levels due to health considerations, but also because of the necessity to increase the efficiency of the devices.

Heat loss related to the presence of combustible substances in the gas mixture leaving the combustion chamber is referred to as the incomplete combustion loss. Incomplete combustion may be a result of a number of factors, such as insufficient penetration of the combustion chamber by air, insufficient mixing of the volatiles and the oxidator, low temperature in the combustion area, etc. [2]. In each of the cases listed above, concentration of carbon monoxide, hydrogen and volatile hydrocarbons in the exhaust increases.

Some countries such as Denmark have extensive experiences in the field of practical and theoretical studies regarding low-power biomass batch boilers [7]. In Poland, many heating units such as straw-fired units

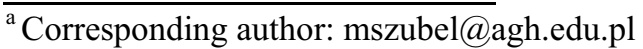


are based on Danish designs. Despite the robust structure, reliability and simple handling, improvement in the field of $\mathrm{CO}$ emission is still necessary.

Both experimental and numerical methods are broadly applied in the studies of the solid biomass combustion process and, as a consequence, are used to achieve higher levels of energy conversion in the exploitation of heating devices.

Authors of [8] present experimental studies of straw and two herbaceous crops combustion in a fixed bed reactor. A wide range of air flow-rates has been used to determine the optimal process conditions. Based on the measured temperatures, gas composition and mass loss, combustion characteristics in terms of ignition front speed, burning rate, percentage of mass loss and the equivalence ratio have been determined. The relation between the air flow-rate and the stages of the combustion process has been established.

The paper [9] presents the results of the experimental studies of a batch boiler designed to burn pellets in order to evaluate the influence of the air staging used in the combustion process on the volume of $\mathrm{NO}_{\mathrm{x}}$ emissions. Temperatures have been measured in selected points of the combustion chamber and the analysis of the $\mathrm{CO}$ content in the exhaust has been performed for different conditions. The results enabled the development of a set of recommendations for optimizing the operation of the unit.

Another approach is to study the process of biomass combustion independently from the operation of the device, in a laboratory. An adequate example is provided in [10], where a laboratory evaluation of four different pulverized biomass types was described. Single particles of sugarcane bagasse, pine sawdust, torrefied pine sawdust and olive residue were burned in a drop-tube furnace, set at $1400 \mathrm{~K}$, in both air and $\mathrm{O}_{2} / \mathrm{CO}_{2}$ atmospheres containing different oxygen mole fractions. High-speed and high resolution images of single particles were recorded and temperature-time histories were obtained pyrometrically. Striking differences were observed between the combustion behavior of the biomass particles burned in that study and those of coal particles of all ranks investigated in previous studies in this laboratory. The biomass particles released large amounts of volatiles that burned in the form of spherical envelope flames.

One of the essential tools used to analyze the dynamics of combustion of this type of biomass is the thermogravimetric analysis (TGA). Among other things, such method allows to determine the energy consumed in the thermal decomposition of the fuel components, as well as to establish the rate of the process in a given temperature. Moreover, the TGA provides information related to the influence of the fuel composition on the combustion and thermal stability of the biomass. Based on the results obtained by means of this method, it is also possible to develop a combination of the reactions used in the combustion mechanisms included in the numerical models [11 - 13].

In works described in [14], an Euler-Euler multiphase CFD model is presented as a method of simulation of continuous fast pyrolysis of the biomass in a fluidized bed reactor. Multi-component, multi-stage kinetic model is applied to describe the pyrolysis of the biomass particle. Direct relation with the experimental (TGA) works is considering the biomass as a mixture of three pseudocomponents (cellulose, hemicellulose, and lignin) in case of the numerical model.

Authors of [14] present a three-dimensional numerical model of a straw boiler which has been developed to allow for the optimization of the structure and the operation conditions. Combustion in oxygen-enriched or conventional air atmospheres has both been considered. In the study, a combination of FLIC (Fluid Dynamic Incinerator Code) code and FLUENT commercial software has been applied. The goal of using the oxygenenriched atmospheres was to promote the destruction of most pollutants due to the high oxygen partial pressures and temperatures which is reflected by very low residual amounts of organic combustion by-products in the bottom ash and flue gas of the straw-fired boiler unit.

Based on a review of the literature, it must be stated that both experimental and numerical methods may be used as essential tools in the optimization of design and operation parameters of biomass-fired heating devices. The research described in this article is devoted to the impact of the air feeding system design on the $\mathrm{CO}$ emission in case of the $180 \mathrm{~kW}$ straw boiler. Experimental and numerical (CFD) methods have been applied to investigate the $\mathrm{CO}$ emissions in a state-of-theart biomass boiler and to develop a more efficient design of the air supply system without the necessity to introduce significant modifications in the boiler design or to use a second fan.

\section{The tested heating device and the test stand}

The main element of the system used for the experimental works described in the paper is the solid biomass batch boiler (Ekopal RM40 model).

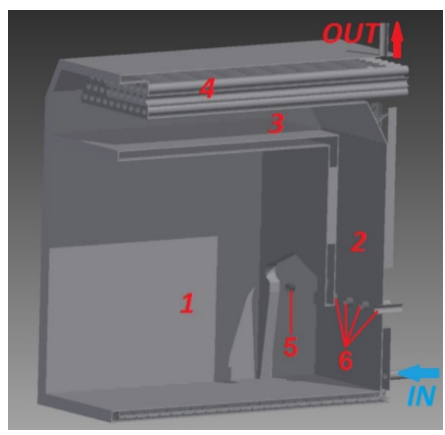

Figure 1. Cross section of the studied biomass batch boiler: 1 - primary combustion chamber, 2 - secondary combustion chamber, 3 - ash separator, 4 - exhaust heat exchanger, 5 - secondary air nozzle, 6 - primary air nozzles.

The EKOPAL RM40 boiler (figure 1) is a $180 \mathrm{~kW}$ unit classified in the group of gasification boilers. The dimensions of the primary combustion chamber are: 2405/3075/1880 $\mathrm{mm}$ (height/width/depth). The device is designed to burn straw in the form of cubes or bales (in the latter case the bale is loaded into the chamber using a 
forklift truck). Co-firing of straw with other biomass fuels and combustion of alternative fuels such as wood wastes is also possible $[15,16]$.

The combustion of fuel proceeds in two stages: in the primary combustion chamber and the secondary combustion chamber. In the first stage, gasification of the fuel in the primary chamber takes place under controlled air deficiency. Combustible gaseous products of the first stage flow into the secondary chamber, where the postcombustion occurs. The next element behind the secondary combustion chamber and the ash separator is a heat exchanger, consisting of tubes arranged in three rows.

The heat exchanger is responsible for the removal of the heat from the exhaust gas (from the process of the combustion of the gasification products). The separation of the combustion stages as well as the application of the exhaust heat exchanger causes an increase in the total efficiency of energy conversion - in case of the heating unit used in the experiments it is approximately $84 \%$ (for the nominal conditions of operation) [17].

It is important to provide a sufficient distribution of air in the areas of the two combustion chambers. The boiler system is equipped with an air supply system, which uses a centrifugal fan and an air manifold in the form of pipes arranged in series (figure 2.), connected with the main pipe responsible for the transport of the air provided by the fan to each duct terminated by the nozzle. Efficient biomass combustion is realized by the proper location of the nozzles of the air manifold (figure 3 ). The air distributor of the examined boiler consist of seven pipes (R1-R7), welded on the front of the main duct, connected with the area of the primary combustion chamber. The last two ducts (D1, D2) are responsible for the feeding of air to the secondary combustion chamber [18]. This is the so called "counter-combustion system", which assures the correct process of straw gasification and combustion of the generated syngas.

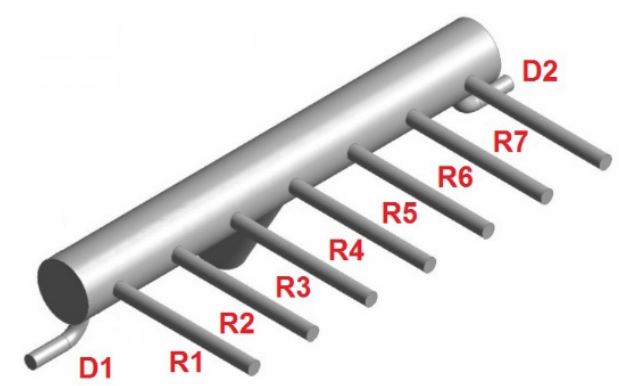

Figure 2. Air manifold applied in the EKOPAL RM40 boiler: R1-R7 - primary air ducts, D1-D2 - secondary air ducts.

The combustion chambers are surrounded by a water jacket filled with water. The jacket is responsible for the transfer of the heat resulting from the combustion and its transportation to the buffer tank. Boilers of this type operate only in open hydraulic systems.

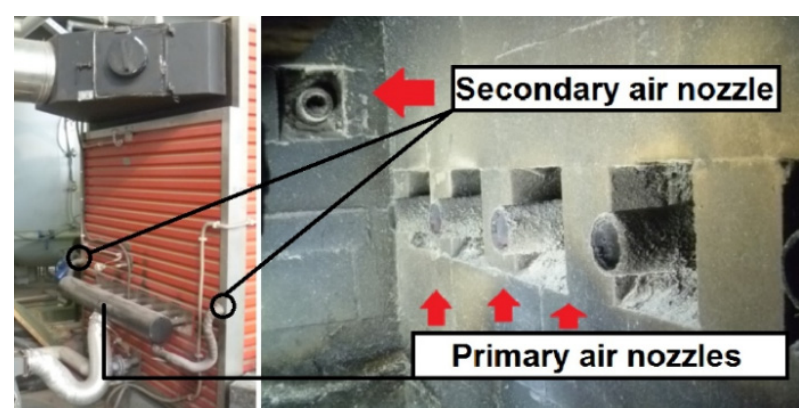

Figure 3. Location of the air manifold at the rear wall of the boiler and the view of the air pipes from the inside of the combustion chamber.

The boiler is fitted to the heating installation via a storage tank. The system of the heating unit connected to the buffer tank is presented in figure 4 . The operating medium, which flows through the water jacket and between the boiler and the buffer tank, is pumped by a pump equipped with an inverter controlled by PLC. The maximum volume flow rate is $8.5 \mathrm{~m}^{3} / \mathrm{h}$. The water volume of the primary loop (including the water jacket, buffer tank and pipes) is about $5.5 \mathrm{~m}^{3}$ [19].

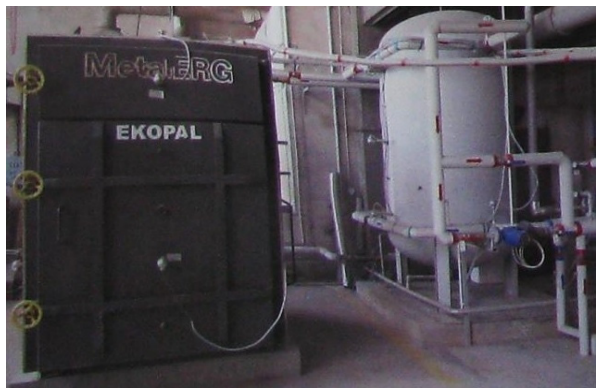

Figure 4. General view of the measurement installation with the batch boiler and the buffer tank.

A storage tank of a proper size is very important in terms of the efficient operation of the heating system due to the requirement of the appropriate heat capacity of the system and the safety of operation (risk of overheating) [20].

To perform measurements of the temperature inside the combustion chambers, PTTK thermocouples have been applied. Five sensors have been selected to control the temperature during the operation of the boiler. The locations of the temperature measurement points (figure 5) has been provided below: DR - the centre of the door of the primary combustion chamber, PR1 - the centre of the right wall of the primary combustion chamber, LE the centre of the left wall of the primary combustion chamber, TY - the rear wall of the boiler, at about $1 / 3^{\text {rd }}$ of the height of the vertical area of the secondary combustion chamber (inlet to the secondary combustion chamber), PR2 - top part of the right wall of the secondary combustion chamber.

A MRU ECO 3000 exhaust analyzer has been applied during the experimental tests. The device is dedicated to the measurements performed in combustion installations, especially in power plants, chemical industries, refineries and laboratories. The analyzer is an essential tool in studying the emissions in case of boilers, hearths, engines 
and turbines. The device is adapted to analyze all popular solid fuels, including biomass.

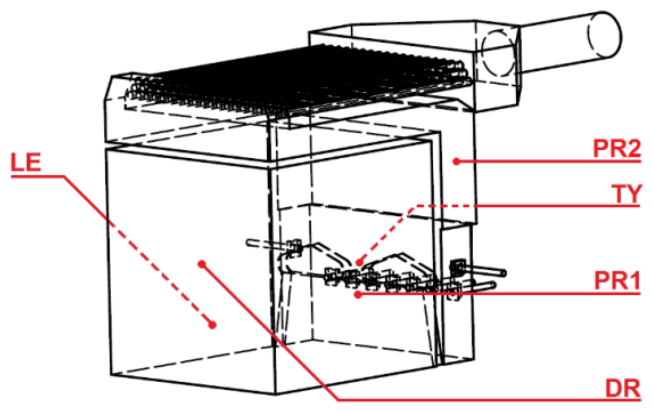

Figure 5. Locations of the temperature sensors in the boiler.

The exhaust analyzer allows to conduct a simultaneous measurement of 10 compounds. Additional parameters are also calculated based on the information from the measuring system. Moreover, the measuring system is equipped with a set of sensors not directly used in the current studies, such as resistance thermometers dedicated to measure the temperature in selected points of the water jacket, the pipes and in the flue. A flow meter and a heat meter are installed in the system. The current heating power of the device can be calculated based on the information provided by the elements of the system mentioned above.

A PLC set is the heart of the control and measurement system. It incorporates a controller connected to a PC and a set of inverters (responsible for the modulation of the operation of the fan and the pumps). The controller consist of modules which receive (from the sensors) and send (to the PC and other devices in the system) an analog and digital signal.

\section{Experimental and numerical analysis of the current state of the heating device}

Experimental tests of the combustion in case of the current state of the heating device have been carried out as the first stage of the study in order to analyze the dynamics and repeatability of the process. Three series of experiments have been carried out. Before each measurement, warming of the boiler has been carried out to provide appropriate conditions during the proper test.

Straw in form of cubes $(700 \times 500 \times 500 \mathrm{~mm})$ has been used. Estimated fuel weight for the individual test was 40 $\mathrm{kg}$ (about $1 / 4^{\text {th }} \sim 1 / 3^{\text {th }}$ of the nominal load). Moisture content in each straw cube has been measured using a device equipped with a bayonet probe. The average moisture content for the fuel used in the experiment carried out for the current state of the boiler (first stage of the study) as well as for the modified air supply nozzles are presented later in the paper.

In each series of measurements, the straw cubes were arranged in the same way. Ignition has been initiated through a special orifice located at the rear bottom corner of the boiler side wall. To ensure the appropriate operation of the heating device, the fan efficiency has been modulated in the same way in each of the experiments. After a given time (about thirty seconds after the ignition) necessary for the flame propagation on the rear wall of the fuel load, the fan efficiency was set to a minimum value $-20 \%\left(\sim 50 \mathrm{dm}^{3} / \mathrm{s}\right)$.

Figure 6 presents selected results of two experiments performed for the current design of the device. Temperature curves allow to determine the stages of the combustion process. Ignition at the rear wall of the fuel load occurs approximately in the $5^{\text {th }}$ minute of the process. In the first 10 minutes of the experiments, the increase of the temperature at the inlet to the secondary combustion chamber ("TY" sensor) is observed. At the same time, an increase of the temperature at the top of the secondary chamber ("PR2" sensor) occurs. The $\mathrm{CO}$ emission curve behaves in a manner analogous to the "TY" temperature curve until the moment when the temperature reaches the highest level - between 700 and $800^{\circ} \mathrm{C}$.
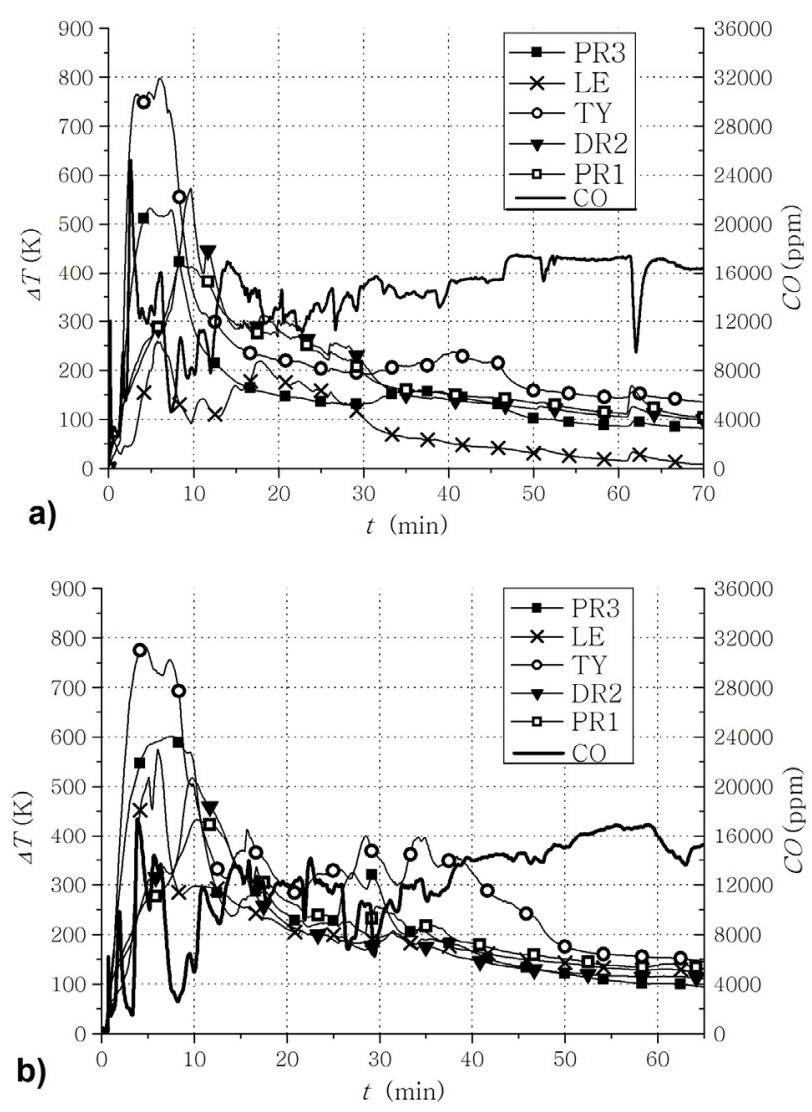

Figure 6. Results obtained in the first (a) and the second measurement (b) of the current design of the boiler.

The high content of $\mathrm{CO}$ in the first stage of the combustion is due to the fact that the fuel is a natural barrier closing access to the primary combustion chamber. Consequently, the area of the oxidation of the gasification products is reduced almost exclusively (depending on the fuel load) to the region of the secondary chamber. In the time of the highest temperature in the secondary combustion chamber the emission level decreases rapidly, which is the result of the conditions appropriate for the $\mathrm{CO}$ post-combustion. The temperature in the secondary chamber is relatively high, the combustion area moves in the direction to the 
door and the temperatures in the center of the reactor (especially "PR1" sensor) increase. Moreover, the combustion proceeds in a larger part of the primary combustion chamber.

The emission of $\mathrm{CO}$ increases slightly in the third stage of the combustion, when the temperatures in the measurement points decrease to the level below approximately $250 \sim 300{ }^{\circ} \mathrm{C}$. Based on the temperature curves for the fuel load used in the analyses in concern, the following stages of the process can be distinguished: - ignition stage till the $5 \sim 10^{\text {th }}$ minute of the measurement, - nominal (proper) combustion stage till the $30 \sim 35^{\text {th }}$ minute of the measurement,

- afterburning of the solid residues after 35 minutes.

A numerical CFD model has been developed to analyze the phenomenon occurring at the beginning of the combustion in the area of the secondary combustion chamber. Fluid dynamics as well as the simple combustion model allowed to refer the experimental results to the air flow characteristics obtained by means of computation. Commercial tools included in the ANSYS Workbench 15 software have been applied for the geometry edition, computational grid generation as well as in problem solving.

Due to the fact that the first stage of the combustion proceeds generally in the area of the secondary combustion chamber, 3D geometry designed for the purposes of the analysis was reduced just to that region of the device (thus the primary combustion chamber has not been considered). In case of the spatial geometry corresponding to the current (existing) design of the boiler, it was also possible to reduce the geometry to that half of the device, due to the presence of the symmetry plane.

Spatial geometry has been divided into sections, allowing for the efficient discretization with the predominance of hexagonal grid elements. Subsequently, the geometry has been exported to the ANSYS Meshing. Discretization has been carried out using the "Multizone", the "Hex dominant" and the automatic method. The total number of grid elements was $1.3 \cdot 10^{6}$. The computational domain has been defined as the continuous fluid and the reacting mixture. Due to the fact that the goal of the study was to investigate the possibility of reducing $\mathrm{CO}$ emission by modifying the air feeding system, the volatiles have been defined as a mixture of $\mathrm{CO}$ and $\mathrm{H}_{2} \mathrm{O}$. Air was represented by a mixture of $\mathrm{O}_{2}$ and $\mathrm{N}_{2}$. The kinetics of the chemical reaction were based on the "Finite Rate Chemistry and Eddy Dissipation" model, which gives consideration to turbulences as well as the temperature in the reacting mixture. In such approach, the level of mixing of the fuel and the oxidizer is also significant. The mechanism of the $\mathrm{CO}$ postcombustion has been based on the Arrhenius equation. Kepsilon model of turbulence has been applied.

Heat transfer was taken into account in the model. An appropriate heat transfer coefficient has been defined for the walls of the combustion chamber $-80[\mathrm{~W} / \mathrm{m} 2 \mathrm{~K}]$ for the bottom part covered by the chamotte bricks and 150 $[\mathrm{W} / \mathrm{m} 2 \mathrm{~K}]$ for the top part in direct contact with the water jacket ( $8 \mathrm{~mm}$ steel wall). The Discrete Transfer option for the thermal radiation has been set with the so-called "surface to surface" mode and the "Multigray" spectral model.

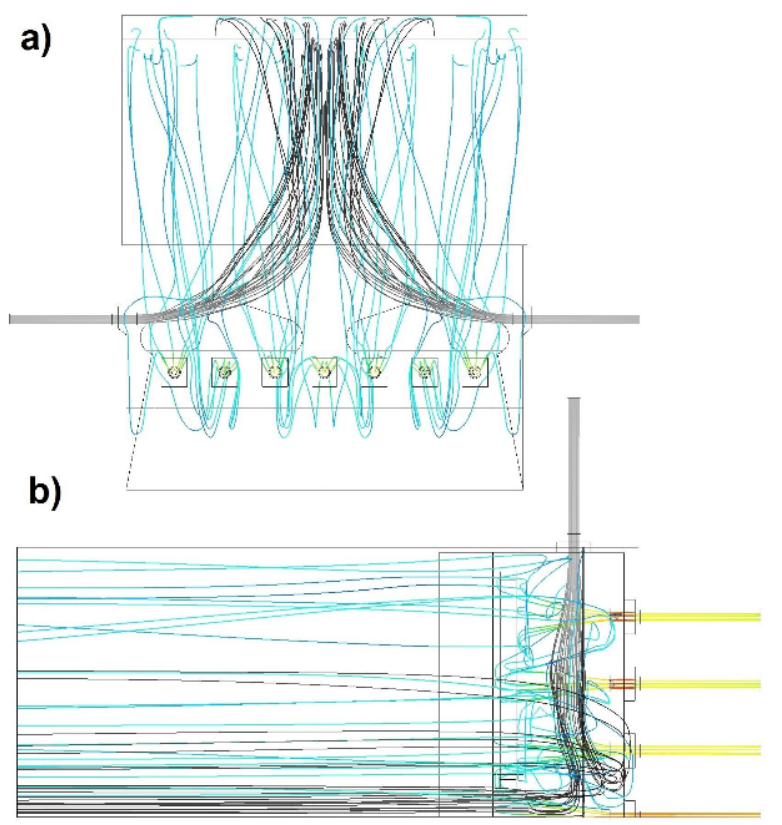

Figure 7. Streamlines of the primary (rainbow scale) and the secondary (grayscale) air in the secondary combustion chamber in case of the existing boiler.

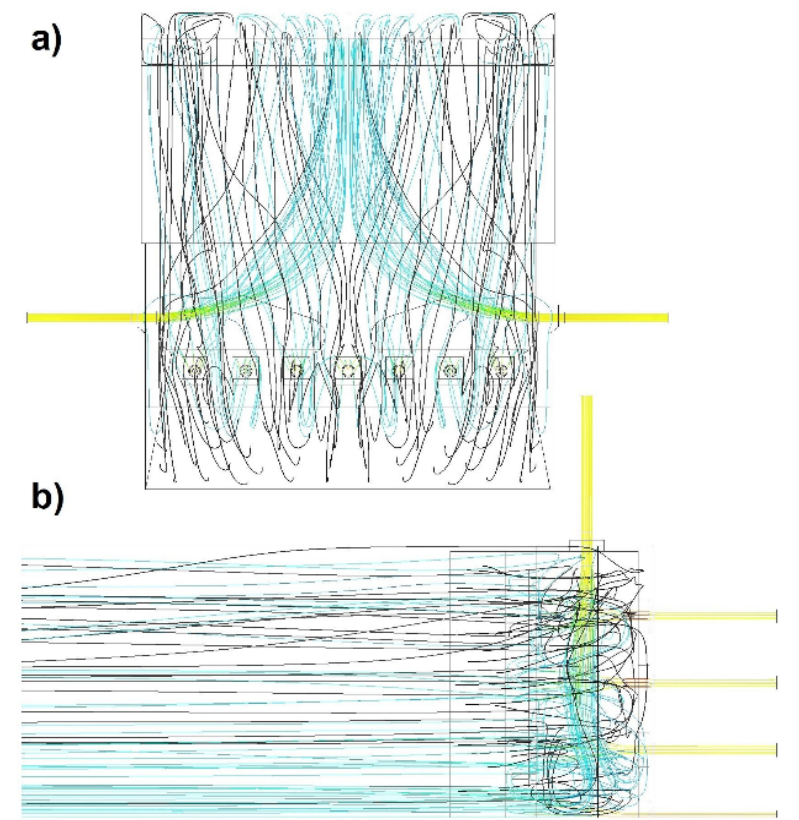

Figure 8. Streamlines of the primary and the secondary air (rainbow scale) and the CO (grayscale) in the secondary combustion chamber in case of the existing boiler.

Because of the non-homogeneous air distribution along the pipes of the air manifold, the primary and the secondary air inlets have been set as individual boundary conditions [18]. The highest value of the mass flow was set for the central pipe, located on the symmetry plane of the geometry and for the secondary air nozzles, 0.0237 $\mathrm{kg} / \mathrm{s}$ and $0.0239 \mathrm{~kg} / \mathrm{s}$, respectively. The mass flow for 
other ducts oscillates around $0.0235 \mathrm{~kg} / \mathrm{s}$. Based on the manufacturer's recommendations regarding the exploitation of the studied device, the chimney draft for the model has been set to $-40 \mathrm{~Pa}$ ("opening" type outlet boundary condition).

Steady state analysis has been carried out. The residues for the governing equations has been set on the level $1 \cdot 10^{-5}$.

The analysis has been carried out especially to determine the characteristics of the air fluxes in the area of the secondary combustion chamber.

Figure 7 presents the so-called streamlines generated using the options available in the post-processor of the ANSYS CFX. The lines correspond to the primary and secondary air streams in the aforementioned space. The configuration of the nozzles results in a laminar flow of the air - especially in case of the secondary air which is responsible for the post-combustion of the CO.

The location of the secondary air nozzles opposite to each other suggests that the level of the turbulences in the place of the collision of the streams has to be high, but due to the width of the chamber and the impact of the chimney draft the air flows up to the outlet from the post combustion area.

Due to the characteristics of the air flow, the mixing of the $\mathrm{CO}$ and the oxygen in the considered case is much more difficult. The relation between the fluxes of the air and the volatiles is shown in figure 8 . The characteristics of the air flow result in high concentration of the $\mathrm{CO}$, especially in the regions close to the side walls. CO emission calculated within the numerical simulation is equal to $2.6 \%$ (averaged mass fraction at the outlet of the computational domain). The effect can be reduced by the change of the air flow directions, which in some cases does not require any major modification of the heating device design and can also be applied in already existing boilers.

\section{Experimental and numerical analysis of the heating device equipped with the modified secondary air feeding system}

Many methods are available to achieve mixing improvement and, consequently, a better post combustion of the CO. According to the presented results of experimental measurements, the temperature in the combustion area is a significant factor which has direct impact on the chemical reactions in this region. However, the application of additional insulation surfaces on the wall of the secondary combustion chamber requires a modification of the water jacket design due to a significant decrease of the efficiency of the heat transfer through the internal walls to the operating medium.

On the other hand, in [19] significant problems related to the overheating of some areas of the studied type of biomass boilers have been described. Therefore, the insulation of the parts of the device which are prone to overheating is reasonable from the point of view of the $\mathrm{CO}$ emission and the overheating risk. It has to be noted that this approach is possible only in case of new devices. For the existing heating units, it is necessary to develop technically reasonable and cost-effective methods of optimization of the $\mathrm{CO}$ post-combustion of the boilers.

Due to the fact that the source of the problems related to the $\mathrm{CO}$ emission is strongly connected with the inefficient mixing of the secondary air and the volatiles, a modification of the secondary air feeding system seems to be interesting method to achieve the increase of the efficiency of the energy conversion.

Of course, the implementation of the construction elements responsible for the changing of the air stream direction can cause an increase of the resistance to flow. However, minor changes of the angles of the secondary air nozzles relative to the walls can cause a significant increase of the turbulences in the secondary combustion chamber.

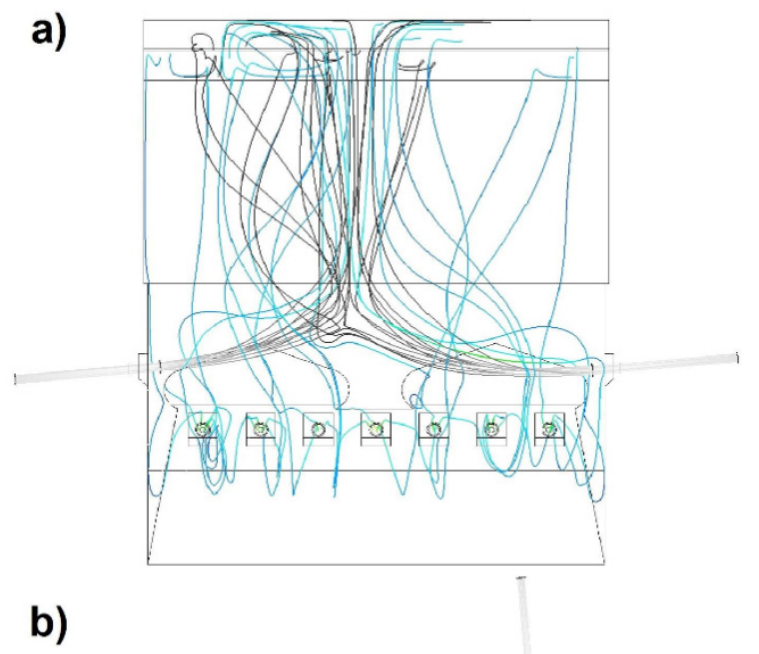

Figure 9. Streamlines of the primary (rainbow scale) and the secondary (grayscale) air in the secondary combustion chamber in case of the first modification of the secondary air nozzles.

As a first stage of the optimization of the combustion process, the proposed design changes have been applied in the numerical model (based on the model developed to study the current state of the considered heating device) to investigate the reasonability of the modifications of the existing heating device and the performance of the experimental studies. It was decided that two configurations will be tested. In the first case: a deflection of the secondary air nozzles of $5^{\circ}$ vertically and horizontally, in the second case: an analogous deflection of the secondary air nozzles of $10^{\circ}$. 
Figs. 9 to 12 show the results of the simulations that have been performed. It was noted that in case of the first modification (deflection of $5^{\circ}$ ), the relation between both air fluxes as well as between the air fluxes and the $\mathrm{CO}$ flux is much more preferred that in the case of the existing air feeding system.

The angled air fluxes generate a vortex in the centre of the secondary combustion chamber. The turbulent flow region is moved slightly towards the left sidewall of the chamber, which is a result of the manner of vertical deflection of the nozzles. Compared to the existing device, in case of the nozzles modification a much larger part of the secondary combustion chamber is characterized by the preferred process conditions. In case of the considered change of the design of the secondary air feeding system, a reduction in the $\mathrm{CO}$ emission by $15 \%$ has been achieved as the result of the numerical simulation.

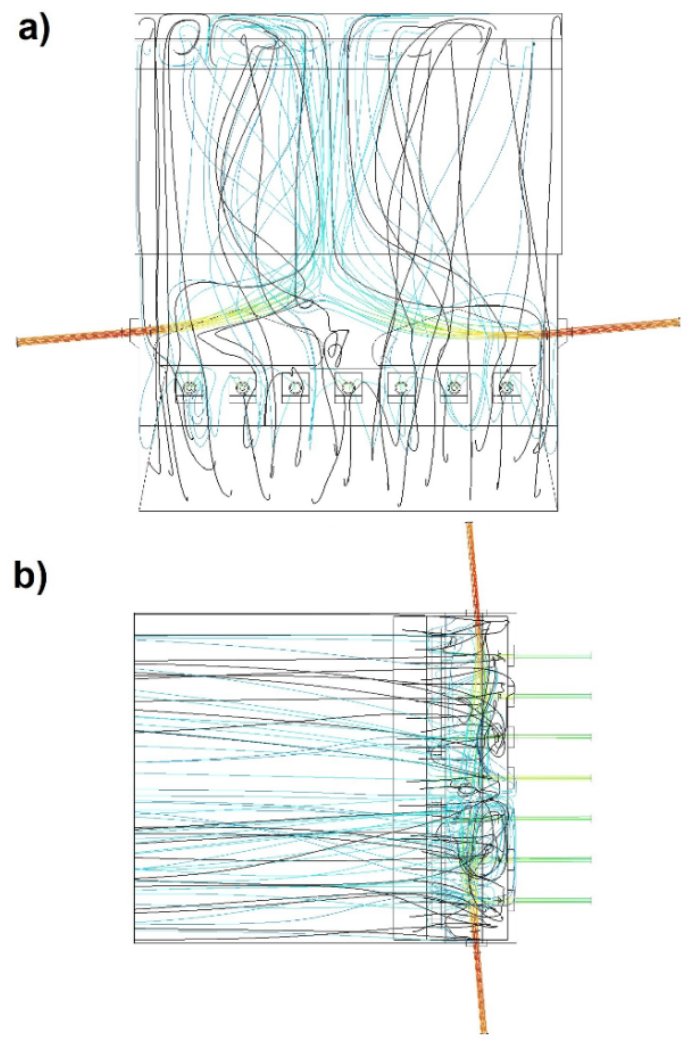

Figure 10. Streamlines of the primary and the secondary air (rainbow scale) and the CO (grayscale) in the secondary combustion chamber in case of the first modification of the secondary air nozzles.

As a second stage of the numerical analysis, secondary air nozzles with an inclination of $10^{\circ}$ have been implemented in the secondary combustion chamber. The manner of the nozzles deflection was similar to the first case described above.

The increase of the deflection angle resulted in the passing of the secondary air streams without generating any significant turbulences in the area of the most intensive post-combustion of the CO. Moreover, as a result of the air flow, volatiles were transported to the top part of the combustion chamber. The positive effect of the second change of the design, however, is visible in the bottom corners.

The relatively low level of the turbulences in the centre of the chamber allows for a better air penetration in the areas near to the sidewalls, which was more difficult to achieve in the cases of the existing device and the first modification.

Vortices appear also at the outlet of the considered area, but the relatively low temperature in this part of the chamber significantly impedes the chemical reaction of the fuel and the oxygen.

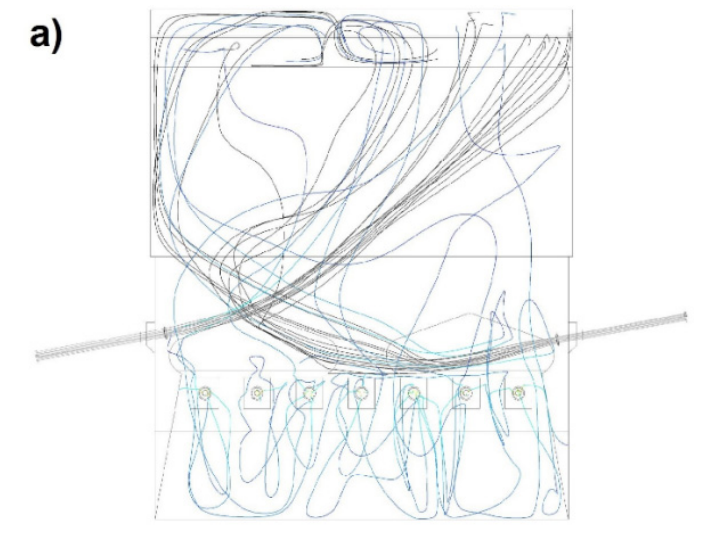

b)

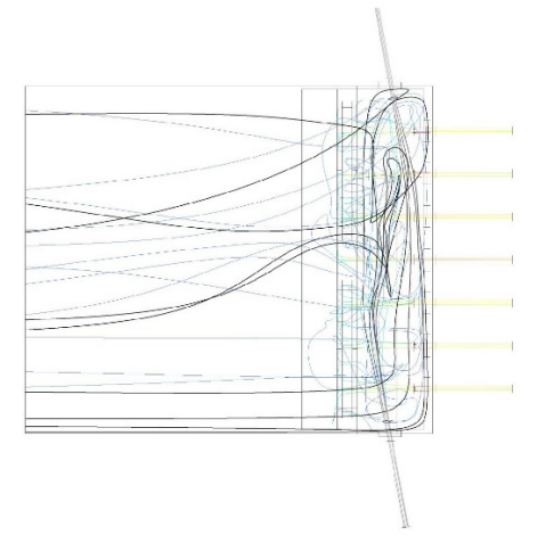

Figure 11. Streamlines of the primary (rainbow scale) and the secondary (grayscale) air in the secondary combustion chamber in case of the second modification of the secondary air nozzles.

The calculated emission level for such case was worse than in the case of the basic design (without any modifications) by about $8 \%$.

Due to the promising results of the simulation devoted to the investigation of the system equipped with the secondary air nozzles deflected by $5^{\circ}$, it was decided to produce a set of steel nozzles based on the design presented in figure 13. One may note that the nozzles have been flattened at their outlets to increase the air velocity and to provide a wider air flux.

The elements deflected by $5^{\circ}$ as well as $10^{\circ}$ have been prepared to compare the results of the experiments with both the numerical simulations performed. The implementation of the newly designed elements of the air feeding system has been carried out by placing them at the ends of the existing secondary air pipes. 
a)

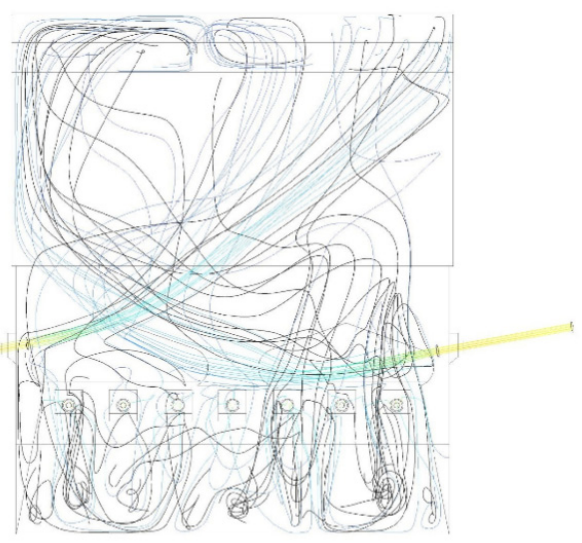

b)

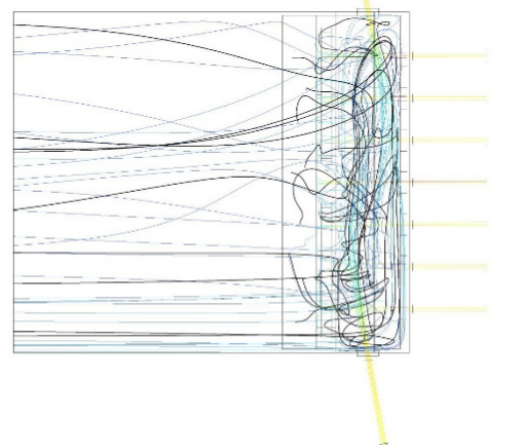

Figure 12. Streamlines of the primary and the secondary air (rainbow scale) and the $\mathrm{CO}$ (grayscale) in the secondary combustion chamber in case of the second modification of the secondary air nozzles.

Due to the fact that the first prototypes of the directional nozzles have been produced using simple methods and tools, the resulting components are slightly different from these assumed in the design (smaller extension at the ends of the nozzles).

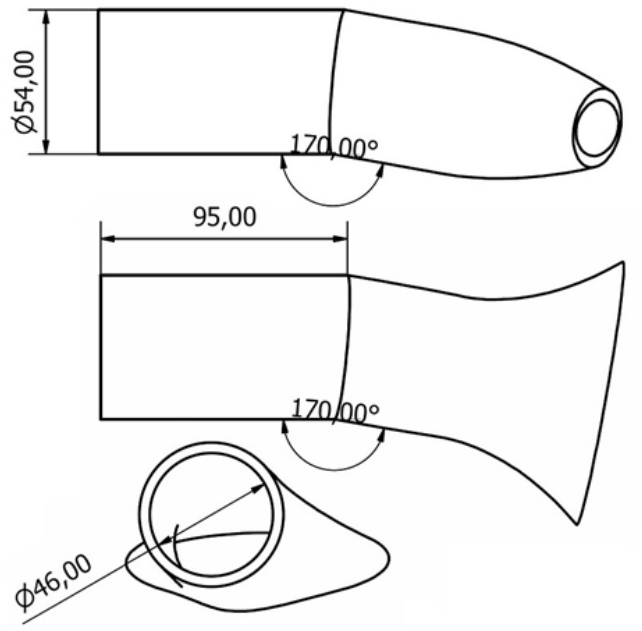

Figure 13. Design of the nozzles produced for the experimental tests (deflection by $10^{\circ}$ ).

Figure 14 shows the directional nozzles which were produced for the experimental tests. The picture presents the elements removed from the secondary air pipes of the boiler after a series of measurements. No thermal deformation or other damages as well as no general wear of the nozzles has been noted.

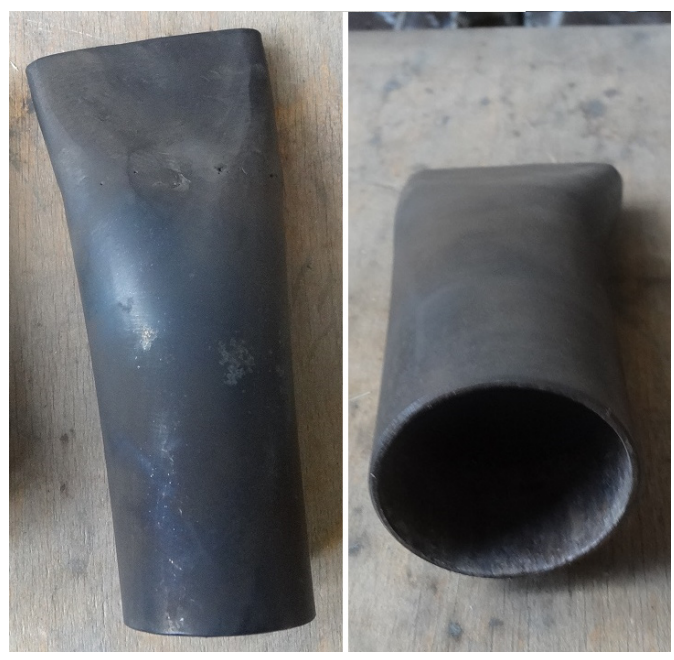

Figure 14. The nozzles produced for the experimental tests removed from the combustion chamber after the measurements.
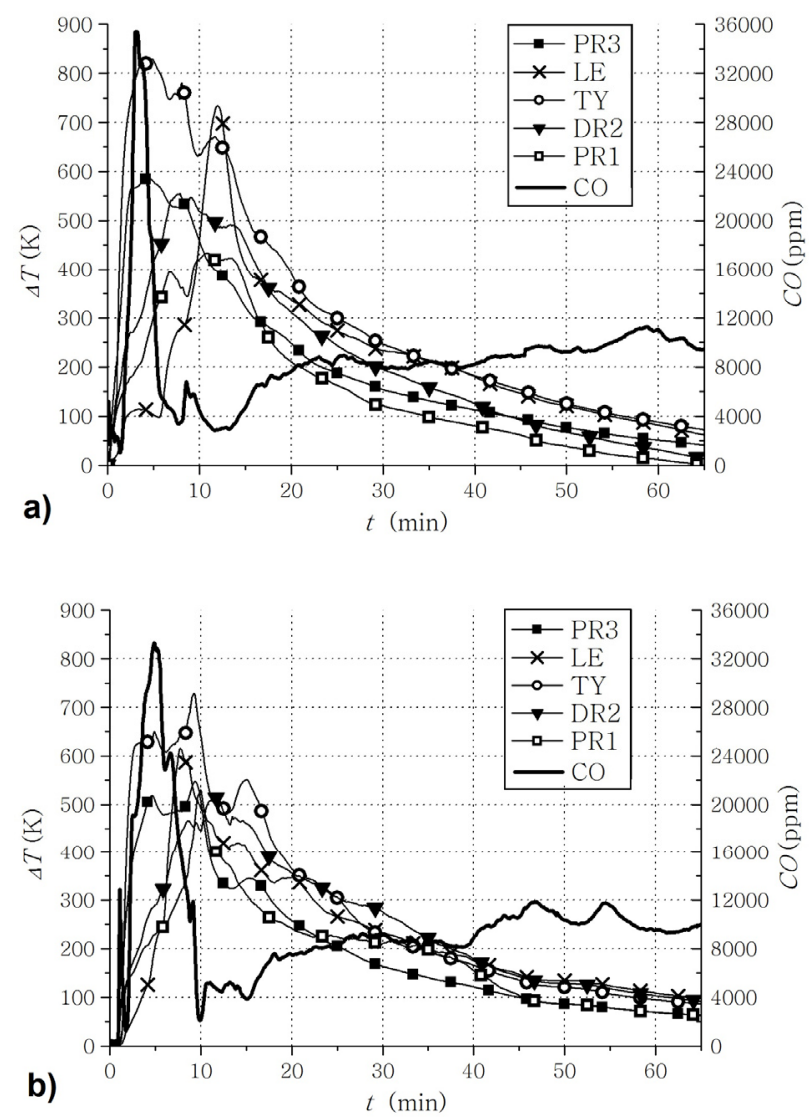

Figure 15. Results from the first (a) and the second measurement (b) of the boiler equipped with the directional nozzles (deflection by $5^{\circ}$ ).

Similarly to the studies of the heating unit before the modifications, three series of experiments have been carried out both for the operation of the boiler with the first and the second design of the directional nozzles (5 and 10 degrees). Each series included the warming up of the device and the proper experiment. Figure 15 shows the results of the measurement for two sample 
experiments performed for the nozzles deflected by 5 degrees.
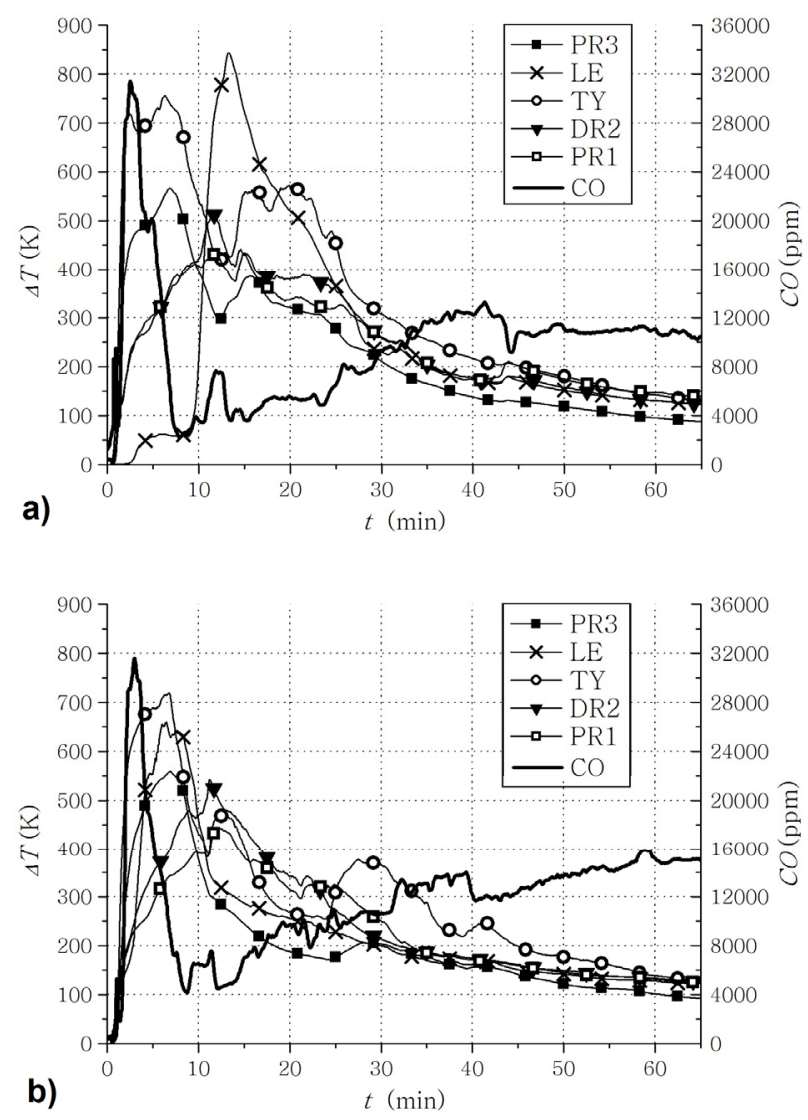

Figure 16. The results of the first (a) and the second (b) measurement of the boiler equipped with the directional nozzles (deflection of $10^{\circ}$ ).

As in the case of the basic design, the process was very repetitive due to the similar arrangement of the straw bales inside the primary combustion chamber. According to the conclusions drawn from the numerical modeling, the application of the directional nozzles results in a significant reduction of the $\mathrm{CO}$ concentration in the exhaust gas. However, in comparison with the basic design (lack of the nozzles deflection), a much higher emission of $\mathrm{CO}$ at the ignition stage has been noted in each series of experiments. Such a situation may be explained by the dynamics of the temperature changes. The temperatures at the measurement points located in the secondary combustion chamber were comparable to the values achieved in the case of the basic design.

On the other hand, it should be noted that the temperatures measured by the sensors located on the left and/or right wall of the primary combustion chamber increase rapidly from the beginning of the process and achieve much higher values already at the beginning of the stage of the proper combustion. This provides information that the intensity of the process at the beginning is greater and that it proceeds at a wider area than in case of the basic design. Consequently, the release of the products of the biomass thermal decomposition (including the carbon monoxide) is higher.
In case of the experimental data obtained in the analysis of the second set of nozzles $\left(10^{\circ}\right)$, the emission of $\mathrm{CO}$ and its relation with the dynamics of the temperature changes is analogous to the case of the first modification. The curve of the $\mathrm{CO}$ emission for the first series of measurements is similar to the one in the previous case. However, the averaged results obtained for the stage of the proper combustion and for the last part of the process are worse than in case of the smaller angle of the deflection of the nozzles. Moreover, a slight randomness in the experiments related to fuel parameters such as local moisture content has to be taken into account. Averaged moisture contents for the straw used in all series of the experimental studies presented in the paper are summarized in table 1.

Table 1. The results of the measurement of the moisture content in the fuel used in the experiments.

\begin{tabular}{|c|c|c|c|}
\hline $\begin{array}{c}\text { Measurement } \\
\text { series }\end{array}$ & $\begin{array}{c}\text { Current state } \\
\text { (no nozzles) }\end{array}$ & $\begin{array}{c}\text { Nozzles } \\
5\end{array}$ & $\begin{array}{c}\text { Nozzles } \\
10^{\circ}\end{array}$ \\
\hline 1 & $12.6 \%$ & $11.4 \%$ & $10.1 \%$ \\
\hline 2 & $12.8 \%$ & $9.5 \%$ & $8.6 \%$ \\
\hline
\end{tabular}

\section{Discussion}

In case of biomass batch boilers, it is possible to improve the degree of the energy conversion by means of the application of additional elements of the air supply system. The directional nozzles allow to generate turbulences in the secondary combustion chamber, which is significant from point of view of the post-combustion of the gasification products. Due to the possibility of installation of the nozzles on the existing air ducts, the solution can be easily applied in the heating devices already in operation. In newly designed boilers, such nozzles could become direct structural elements.

However, to provide the most efficient oxidation of $\mathrm{CO}$, it is required to determine the optimal angle of the vertical and the horizontal deflection of the nozzle. Figure 17 shows the comparison of the $\mathrm{CO}$ emission curves for all cases of the air feeding system considered within the studies described in the paper. Each curve has been generated as an average from the results obtained in three series of experiments.

The effect of the significant reduction of $\mathrm{CO}$ content in the exhaust gas has been achieved both in the case of the first and the second deflection angle at the stage of the proper combustion. Greater reduction of the $\mathrm{CO}$ emission has been noted for the nozzles bent at the angle of 5 degrees. In case of the deflection by 10 degrees, results of the experimental studies are inconsistent with the numerical model. The fact that in the case of the CFD model the considerations have been conducted for a steady state, where the $\mathrm{CO}$ source was defined as present in the same, invariable area, could be the cause of the discrepancies between the computation and the experiment.

Temperature curves generated based on the experimental data indicate that the dynamics of the flame propagation were different in the subsequent tests. 
Consequently, the intensity of the $\mathrm{CO}$ emission has varied, which explains the discrepancies in the results.

Moreover, in case of the numerical model, the primary combustion chamber was completely excluded from the consideration.

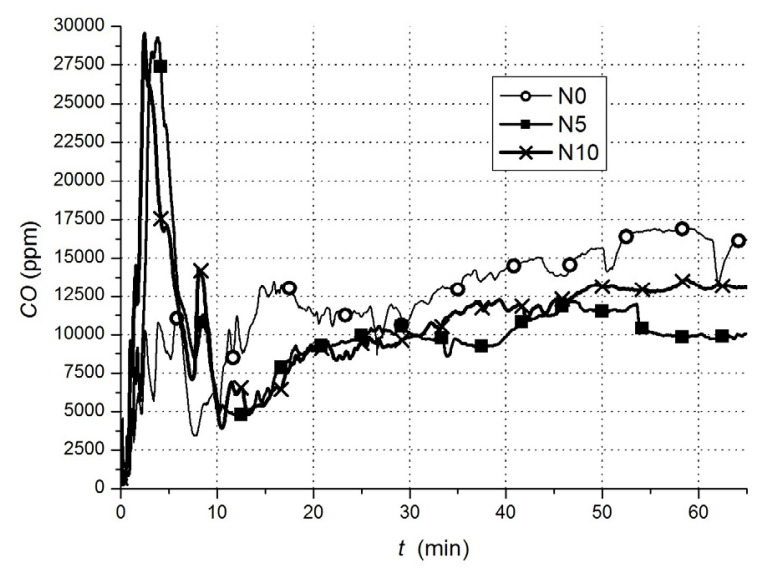

Figure 17. Mean $\mathrm{CO}$ emission curves for all of the considered cases: N0 - basic case, N5 - directional nozzles $5^{\circ}, \mathrm{N} 10-$ directional nozzles $10^{\circ}$.

Experiments were performed for the fuel load smaller than the nominal load and the chemical reactions could take place at the rear region of the primary combustion chamber (the chamber has not been completely cut off).

The location of biomass batch boilers in confined spaces such as the laboratory (the boilers are often installed outside because of their relatively large sizes) may cause exploitation problems related to the possibility of periodic extraction of smoke. For this reason, the ignition of the fuel has to be carried out gradually, which is achieved by appropriately increasing the fan power. The modulation of fan efficiency occurs based on the measurement of temperature curves and the general observation of the boiler operation. Because of this, it is much more difficult to conduct the combustion in the same way in each of the experiments.

Another difficulty related to the numerical modeling of the gasification is the inhomogeneous release of the gasification products from the defined source. While comparing the results of the simulation and the experimental data, randomness related to certain factors such as local moisture content or even fuel density need to be taken into account.

Despite all the problems, a simple CFD model developed within the described works has provided information regarding the characteristics of the gaseous fluxes in the considered area, which allowed to construct a prototype of efficiently operating directional nozzles. Studies carried out using the experimental system of the biomass batch boiler show that the application of the developed elements of the secondary air supply system is economically and technically reasonable.

The increased emission of $\mathrm{CO}$ at the ignition stage suggests that a modification of the process control at that stage has to be considered. It is recommended to apply additional air nozzles at approximately $2 / 3^{\text {rd }}$ of the height of the secondary combustion chamber, which could provide additional secondary air fluxes during the first few minutes of the combustion without the risk of cooling of the bottom part of the combustion chamber, where the process of the biomass gasification takes place. In case of applying the solution referred to above, it is also recommended to reduce the heat transfer to the water jacket in the area of the bottom part of the secondary combustion chamber, to homogenize the process conditions in the entire vertical part of the chamber space.

\section{Acknowledgment}

This study was carried out under the "BioORC: Construction of cogeneration system with small to medium size biomass boilers" project.

\section{References}

1. S. B. Kang, J. J. Kim, K. S. Choi, B. S. Sim, Renew. En., 54, 2-7 (2013)

2. R. Saidur, E. A. Abdelaziz, A. Demirbas, M. S. Hossain, S. Mekhilef, Renew. and Sust. En. Rev., 15, 2262-2289 (2011)

3. A. Demirbas, Progr. in En. and Comb. Sci., 30, 219230 (2004)

4. B. Janković, Cellulose, 21, 2285-2314 (2014)

5. B. Sørensen, Renewable Energy. Its physics, engineering, environmental impacts, economics \& planning, 473-479 (2000)

6. W. Kordylewski, Spalanie i paliwa (in Polish), 3031 (2008)

7. E. F. Kristensen, J. K. Kristensen, Biom. and Bioen., 26, 561-569 (2004)

8. A. Khor, C. Ryu, Y. Yang, V. N. Sharifi, J. Swithenbank, Fuel, 86, 152-160 (2007)

9. H. Liu, J. Chaney, J. Li, C. Sun, Fuel, 103, 792-798 (2013)

10. J. Riaza, R. Khatami, Y. A. Levendis, L. Alvarez, M. V. Gil, C. Pevida, F. Rubiera, J. J. Pis, Biom. and Bioen., 64, 162-174 (2014)

11. C. Tenoiro, R. Moya, Therm. Acta, 563, 12-21 (2013)

12. A. Garcia-Maravel, D. Salvachúa, M. J. Martinez, L. F. Diaz, M. Zamorano, Waste Man., 33, 2245-2249 (2013)

13. C. Branca, C. Di Balsi, En.\&F., 17, 1609-1615 (2003)

14. Q. Xue, T. J. Heindel, R.O. Fox, Chem. Eng. Sci., 2440-2452 (2011)

15. J. I. Miguez, J. C. Morán, E. Granada, J. Porteiro, Renew. and Sust. En. Rev., 16, 3867-3875 (2012)

16. S. Werle, R. K. Wilk, Renew. En., 35, 1914-1919 (2010)

17. K. Sornek, M. Tomski, M. Szubel, M. Filipowicz, En. i Bud. (in Polish), 3, 18-25 (2012)

18. M. Szubel, T. Siwek, Tech. Trans., 19, 255-260 (2014)

19. M. Szubel, M. Filipowicz, EFM, 595-602 (2014)

20. U. Stritih, V. Butala, Renew. En., 29, 2011-2012 (2004) 